\title{
Brief Analysis of the Issue of Cross Border Merger and Acquisition in BRICs
}

\author{
Haiyong Ma (Corresponding author) \\ School of Economics and Management, Changchun University of Science and Technology \\ Changchun 130022, China \\ E-mail: mhymark@gmail.com \\ Weiwei Zhang \\ School of Economics and Management, Changchun University of Science and Technology \\ Changchun 130022, China \\ E-mail: zhangsanxue@gmail.com
}

Received: September 23, $2010 \quad$ Accepted: October 7, $2010 \quad$ DOI: 10.5430/rwe.v1n1p43

\begin{abstract}
Based on the theory of cross-border M\&A and the general law of development of international economics, this article analysis the overall trends of BRICs' oversea M\&A activity. At the end of this article, the authors summarized the challenges faced by the enterprises of BRICs and give several advices according the actual situation of China.
\end{abstract}

Keywords: BRICs, Cross Border Merger and Acquisitions, Outward Foreign Direct Investment

Since the Twentieth Century, although developed countries have always been the subject of overseas merger and acquisition, newly emerging economic entities are playing a greater role in international merger and acquisition (Lucy et al., 2010), and especially overseas merger and acquisition of BRICs has aroused great attention. In recent two years, affected by the international financial crisis, the capacity of BRICs in overseas investment has been weakened. Meanwhile, such factors as emergence of new protectionism have become significant challenges to overseas merger and acquisition of BRICs. Nevertheless, shares of BRICs in the global cross-border merger and acquisition trade are still on the increase. Furthermore, according to analysis in "World Investment Prospects Survey", BRICs will play a leading role in revival of foreign direct investment together with US. With increase of BRICs in the amount of overseas merger and acquisition and expansion of the areas of merger and acquisition, BRICs will exert greater influences upon international cross-border merger and acquisition.

Starting out from the general rule of cross border merger and acquisition theory and international economic development and on the basis of analyzing the overall trend of BRICs in overseas merger and acquisition, this article summarizes challenges encountered by enterprises in BRICs in overseas merger and acquisition and searches for resolutions and strategies.

\section{Analysis of the trend of BRICs in overseas merger and acquisition}

\subsection{Analysis of the trend of amount}

For the past few years, overseas merger and acquisition of BRICs has aroused extensive attention. The amount of overseas merger and acquisition of BRICs increased from $\$ 18.19$ billion in 2003 to $\$ 51.224$ in 2007, with an increase of almost three times. The global financial crisis recently has seriously crippled the capacity and motive of quite a large number of transnational corporations of major economic entities in foreign investment, as a result of which their outward foreign direct investment has been generally slowed down (World Investment Report, 2009). However, it needs to be emphasized, although the total amount of overseas merger and acquisition of BRICs recently has been declined, the shares of the four countries in global cross border merger and acquisition have been always on the increase. Since the first quarter of 2009, the total amount of overseas merger and acquisition of BRICs has risen from $12.3 \%$ of the total amount of global merger and acquisition in 2008 to $14.55 \%$. Merely considering the amount of trade, the amount of overseas merger and acquisition of BRICs has risen from $11.2 \%$ in 2008 to $13.4 \%$.

\subsection{Analysis of the trend of industries}


In recent years, distribution of industries for overseas merger and acquisition of BRICs has been on a gradual increase, including such industries as energy, electrical power, science and technology, chemical engineering, medical care and finance, etc. In the first half of 2009, among the ten largest acquisitions by BRICs, seven industries were attributed to energy, coal mine and utility sectors. Although energy, coal mine and utility sectors are not the most active sectors in terms of the amount of acquisition, as far as the total value of acquisition was concerned, these sectors accounted for $40.5 \%$ of the total amount of acquisitions of BRICs in the 78 acquisition cases which involved a total amount of $\$ 41.9$ billion. Except for Brazil, demand on resources was the critical driving factor for domestic and overseas merger and acquisition by BRICs in the first half of 2009. Energy, coal mine and utility sectors occupied an overwhelming superiority in cross border acquisition of the other three countries, respectively $72 \%$ in Russia, $84 \%$ in India and $95 \%$ in China.

\subsection{Analysis of the trend of location of overseas merger and acquisition}

Overseas merger and acquisition by BRICs represents the major trend that emerging markets' cross border merger and acquisition is mainly concentrated in developed countries, especially in China and India. In terms of the degree of concentration, overseas acquisition markets of Indian corporations are mainly concentrated in highly competitive and mature Britain and US. In the first half of 2009, the amount of acquisitions of Indian corporations in North America accounted for $87 \%$ of the total amount of its overseas acquisition, and $11.6 \%$ in West Europe, whereas the amount of acquisitions of Chinese corporations in North America accounted for $51.3 \%$ and $14.5 \%$ in Australia. It is the mature markets in developed countries that enterprises of BRICs acquire enterprises in developed countries and these overseas markets will provide more market access opportunities, marketing channels for large brands and multiple product assortments. Furthermore, developed countries are reserves of advanced technology, thus they are the optimal regional choice for BRICs to acquire technical support by the means of overseas merger and acquisition.

\section{Analysis of challenges to overseas merger and acquisition of BRICs}

\subsection{Threat of protectionism from host countries}

After the outbreak of global financial crisis, nationalism of host countries has been increasingly distinct. Besides, cross border acquisition itself is a topic with high sense of politics, so emerging markets suffer from more serious discrimination and treatment than developed countries in cross border merger and acquisition. For the past few years, with expansion of the scale of cross border acquisition of corporations in BRICs, they have been suffered from more problems of foreign boycott in the process of overseas merger and acquisition. Demand on resources is the critical factor to drive the behavior of acquisition of BRICs both at home and abroad. Acquisitions of these resource industries and some infant industries have received high attention from the government of host countries, and administrative intervention of the government has naturally become one of the major means to prevent foreign corporations from competing with their own corporations by the means of acquisition.

\subsection{Challenges to balance opportunities and risks}

Resource acquisition is one of the important targets for corporations of BRICs to conduct overseas merger and acquisition and decline of resources price exactly caters to this requirement. Thus, investment of BRICs in the Section of Resources has been on a continuous increase in recent years. Obviously, if the market price of resources after acquisition continues to rise, then acquisition and investment of corporations in BRICs will bring generous profit returns. However, high returns are always accompanied with high risks. If the price of resources after acquisition continues to decline, then corporations in BRICs will face up with substantive debt crisis. Likewise, fluctuation of the price of international financial assets is the cause for corporations of BRICs to expand their acquisitions in Financial Section recently. However, financial assets themselves are of great fluctuation and of high risk, there is also great possibility that the price of assets after acquisition of corporations drops. If the price drops, then corporations of acquisitions may be encountered with the risk of great shrink of assets. Therefore, corporations of BRICs need to make appropriate preparation of risk defense prior to their action of acquisitions.

\subsection{Challenges to assume social responsibility}

Existence of economic externality requires corporations to assume corresponding social responsibility, such as protection of the environment, maintenance of natural harmony, realization of sustainable development of saving of resources, etc. In addition, host countries also pin their hope on foreign corporations which conduct overseas merger and acquisitions to bring capital, technology and talents, help them resolve the issue of employment, improve their capacity of scientific innovation and increase financial revenue of host countries. Some corporations of BRICs often ignore corresponding social responsibility after they sign overseas acquisition agreement, and especially some corporations do not perform their promise, as a result of which they come upon against intense denunciation of the media, labor union 
and the government of host countries and finally go to failure in acquisition. Just because of this, the fact that "overseas acquisitions may do harm to local employment and environment" has become one of the major reasons for host countries to limit acquisitions by BRICs of their corporations. It can be seen, whether a host country accepts acquisition and investment depends on whether corporations of BRICs have really assumed their corresponding social responsibility.

\section{Several suggestions}

In order to promote overseas acquisition activities, BRICs and their corporations have to realize the following several aspects:

\subsection{To establish policy supporting system for overseas merger and acquisition of their corporations}

Firstly, BRICs should improve the legal system of overseas acquisitions for their enterprises and confirm industrial and capital requirements on corporate acquisitions. Secondly, BRICs should formulate several supporting policies, such as fiscalit, finance, insurance, foreign exchange and entry and exit, etc, and encourage financial intermediary organs to provide credit support and financial service for enterprises, especially to improve the financial market and broaden financing channels for enterprises. Thirdly, these four countries ought to make perfect their acquisition service system and offer consultations, guidance and agency negotiation, etc, for enterprises of acquisition, encourage schools to foster talents of acquisition and set up mechanism of jointly cultivating talents by enterprises and universities, improve international coordination mechanism and cultivate international communication and coordination mechanism, set up security guarantee mechanism, give full play to the bilateral economic and trade mechanism and bilateral investment protection agreement and guarantee legitimate rights and interests of enterprises.

\subsection{To reinforce transparency of operations of sovereign wealth fund}

Reinforcement of transparency of sovereign wealth fund may help to keep down the continuously rising momentum of protectionism and alleviate worries that these countries may impose inappropriate influences upon global financial market. Reinforcement of transparency of sovereign wealth fund includes providing the following information: auditing annual reports, publicizing investment strategy and target, making public the market capitalization, investment portfolio, realized rate of market returns and the scale of remuneration of funds management personnel, and formulating and abiding by internal moral code of conduct, etc. On the pre-condition of ensuring their own security, sovereign wealth fund of BRICs should improve the transparency according to their own development condition and the principle of gradual and orderly progress. Besides, BRICs need to strengthen the responsibility for sovereign wealth fund to alleviate worries of host countries about the investment and lay a foundation for continuous development of sovereign wealth fund.

\subsection{To assume necessary social responsibility}

Corporations of BRICs need to assume necessary social responsibility in order to eliminate doubts of host countries and to successfully complete the target of cross border acquisition. Firstly, corporations of BRICs have to strictly perform their promise to corporations in host countries prior to their acquisitions and set up good faith to lay good foundation for their cross border operation afterwards. Secondly, BRICs corporations should take an active attitude in participating in public benefit activities of host countries and set up good image. Thirdly, BRICs corporations should take an initiative in holding employment fellowship activities and eliminate contradictions between labor and capital. Finally, the corporations in BRICs should communicate frequently and set up and maintain harmonious relations with the government, media and labor union of host countries. Besides, in order to eradicate particular obstructs and seek for common development, corporations of BRICs may consider migrating their headquarters to host countries or other countries under an extreme circumstance.

\subsection{To formulate rational acquisition strategy}

Overseas merger and acquisitions of corporations in BRICs should be done according to their own abilities, for which they should formulate acquisition strategies that fit with themselves. Compared with corporations acquired, if the corporations that conduct the action of acquisition have obvious ownership superiority, then they may consider adopting solely-invested acquisition mode. However, if a corporation attempts to acquire a foreign corporation with equal power or greater strength, it needs to adopt a joint acquisition mode, and they should especially make a strategic cooperation with European and American developed corporations to win target corporations through the means of joint acquisition. In addition, corporations of BRICs may learn the advanced management experiences and negotiation skills of old brand transnational corporations in the process of cooperation with them. 


\section{References}

Karl P, W., and Geraldine (2010).Foreign Direct Investment from Emerging Markets: The Challenges Ahead .New York: Palgrave Macmillan. (Chapter 1).

Lucy, C., Ivonne, A., and Macias, J. (2010). Changing Direction: Cross Border Acquisitions by Emerging Market Firms.SSRN Working Paper.pp.13-33

Sergey, F., and Kalman, K. (2009).Foreign Direct Investment in Times of Global Economic Crisis: Spotlight on New Europe.UNU-MERIT Working Paper Series.pp.9-21

Singh, L., and Jain, V. (2009). Emerging Pattern of India's Outward Foreign Direct Investment under the Influence of State Policy: A Macro View.MPRA Paper.pp.11-15

UNCTAD.World Investment Report (2009).Transnational Corporations, Agricultural Production and Development. 